\title{
CHONDROSARCOMA OF HUMERUS - METASTASIS TO LUNGS A RARE CASE REPORT
}

\section{Dr.Jishna.G \\ Dr.Sabarinath Ravichandar*}

MBBS,MD,Junior Resident,Department of Pulmonary Medicine,Sree Balaji Medical college and Hospital.

MBBS, MD,MRCP,Diplomate in ERS ,Department of Pulmonary Medicine ,Consultant Pulmonologist,Sree Balaji Medical College and Hospital. ${ }^{*}$ Corresponding Author
ABSTRACT excellent prognosis after adequate surgery.However most of them are chemo or radio-resistant ${ }^{1}$. We report a case of primary chondrosarcoma of proximal humerus in a 52-year-old male who presented with a sixyears history of swelling and restricted range of Motion of right shoulder which later metastasized to the lungs in a span of 4 yrs.

\section{KEYWORDS : Recurrent chondrosarcoma, Proximal humerus, Male,Metastasis to lungs.}

\section{INTRODUCTION}

Primary bone tumours are uncommon and this has certainly contributed to the scarcity of data about their relative frequency, and to the limited understanding of the riskfactors. Overall, bone sarcomas account for $0.2 \%$ of all malignancies, and the adjusted incidence rate for all bone and joint malignancies is 0.9 per 100,000 persons per year,while the 5 year overall survival rate is $67.9 \%$.Chondrosarcoma constitutes a heterogeneous group of neoplasms that have the production of cartilage matrix by tumour cells in common. This primary sarcoma of bone in adults has a male predominance and is well demonstrated between the 3rd and 7th decades of life. Low grade chondrosarcoma has similar appearance to enchondroma and osteochondroma and has occasional binucleated cells. High grade chondrosarcoma has increased cellularity, atypia, and mitoses. ${ }^{2}$

We report a case of a low grade chondrosarcoma of the proximal right humerus in a 52-year old male patient who underwent wide excision and reconstruction with cemented prosthesis which developed into osteomyelitis leading to removal of prosthesis and patient presented with lung complaints after a span of 4years.

Case details :

52 year old male Patient who is a known case of Chondrosarcoma of Right proximal Humerus 4years back presented with complaints of cough with expectoration $\times 2$ months - cough acute in onset, gradual in progression, aggrevated on lying down, relieved on sitting , associated with sputum - scanty, white in colour , non foul smelling and with 1 episode of blood tinged sputum production 1 month ago. Patient also had complaints of breathlessness while climbing stairs - Grade I MMRC. Grade III clubbing present. Smoking Index $=300 . \mathrm{K} / \mathrm{c} / \mathrm{o} \mathrm{T} 2 \mathrm{DM} \mathrm{x}$ 6yrs and on irregular treatment . $\mathrm{K} / \mathrm{c} / \mathrm{o}$ Recurrent chondrosarcoma of Right proximal humerus and closed biopsy of right humerus was done on 29/1/2016 post op wide excision and reconstruction with cemented prosthesis on $04 / 03 / 2016$.

Examination of RS : B/L NVBS, Left Basal crepitations on inspiration, occassional wheeze. Maintained a saturation of $95 \%$ at room air.

Investigations :

MRI of right shoulder on 12-02-2015 showed features s/o osteochondroma with chondrosarcoma transformation.

core biopsy was done on 24-02-2015 showed a low grade chondrosarcoma and excision of tumor was done on 10-032015 under general anaesthesia. later patient presented with similar complaints since 8 months, The patient underwent closed biopsy of right humerus on 29/01/2016

CT humerus on 27-01-2016 revealed k/c/o osteochondroma with malignant transformation.

\section{PET SCAN : 16-02-2016}

Table 1 depicting PET CT findings in different organs.

\begin{tabular}{|l|l|}
\hline Humerus & $\begin{array}{l}\text { Hypermetabolic activity in heterogenously } \\
\text { enhancing soft tissue mass with necrosis and } \\
\text { osteoid matrix involving anterior muscular plane } \\
\text { around proximal and mid shaft of humerus size } \\
70.3 \mathrm{mmx} 76.4 \mathrm{mmxl} 22.6 \mathrm{~mm} \text { partially encasing } \\
\text { and compressing brachial vessels -representing } \\
\text { active disease. }\end{array}$ \\
\hline Axilla & $\begin{array}{l}\text { Nodes in right axilla of largest measuring } \\
11.6 \times 7.5 \mathrm{~mm} \text { - no increased metabolic activity. }\end{array}$ \\
\hline Abdomen \\
and pelvis & $\begin{array}{l}\text { Tiny granuloma in right lobe of liver involving 7 } \\
\text { segment of size measuring - 5.4x 3.7mm - no } \\
\text { increased metabolic activity. }\end{array}$ \\
\hline GIT & $\begin{array}{l}\text { Nodes noted in left paraaortic region of largest } \\
\text { measuring 13.3x 12.2mm - no increased metabolic } \\
\text { activity. }\end{array}$ \\
\hline
\end{tabular}

MRI of right shoulder on 02-03-2016 revealed. chondrosarcoma arising from metaphysis-diaphysis of proximal humerus.Post op wide excision and reconstruction with cemented prosthesis on 04/03/2016.Post operatively he had custom mega prosthesis insitu with discharging sinus from previous incision scar taken up for wound debridement and cement augmentation and IV antibioics continued.

07-09-2020 - CXR - revealed multible cannon ball mets which was corelated with CT scan which depicted a similar picture and a diagnosis of Multiple cannon ball mets - ? mets ? CA. ?TB was suspected.

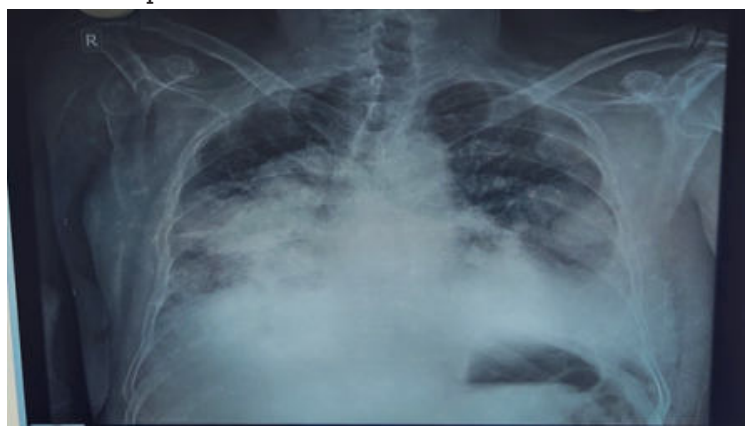

Fig l : 


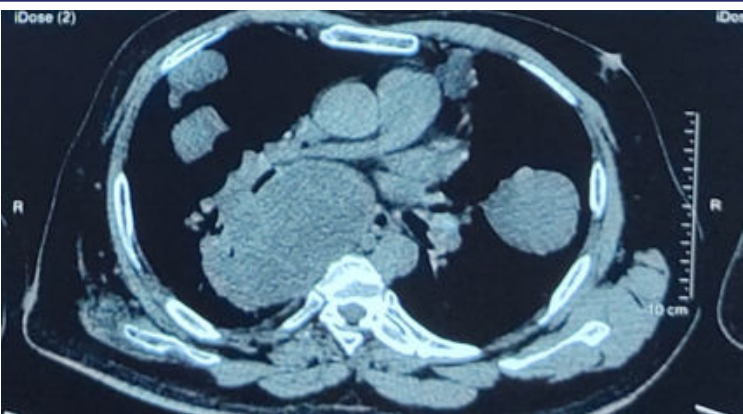

Fig $2 \alpha$

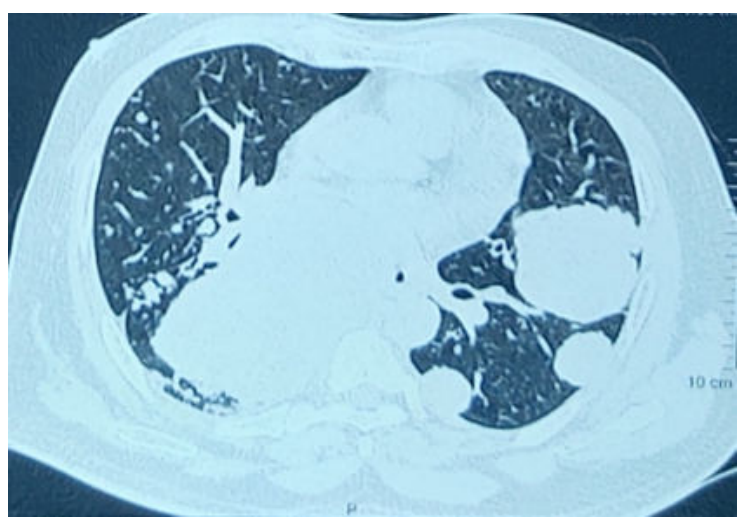

Fig $2 b$

Fig $2 a$ and $2 b$ depicting multiple cannon balls in Ctchest.

CT guided lung biopsy was done on 07-09-2020 - showed features s/o poorly differentiated carcinoma.

IHC was done for further evaluation on 16-09-2020.

\begin{tabular}{|l|l|}
\hline MARKERS & RESULT \\
\hline Ck7 & Negative in atypical cells \\
\hline TTF-1 & Negative in atypical cells \\
\hline S-100 & $\begin{array}{l}\text { Positive in atypical cells within myxoid } \\
\text { matrix }\end{array}$ \\
\hline BCL-2 & Focal Positive \\
\hline SYNAPTOPHYSIN & Positive in cluster of cells \\
\hline
\end{tabular}

IMPRESSION : IHC favours metastatic deposits from chondrosarcoma in $\mathrm{ak} / \mathrm{c} / \mathrm{o}$ chondrosarcoma.

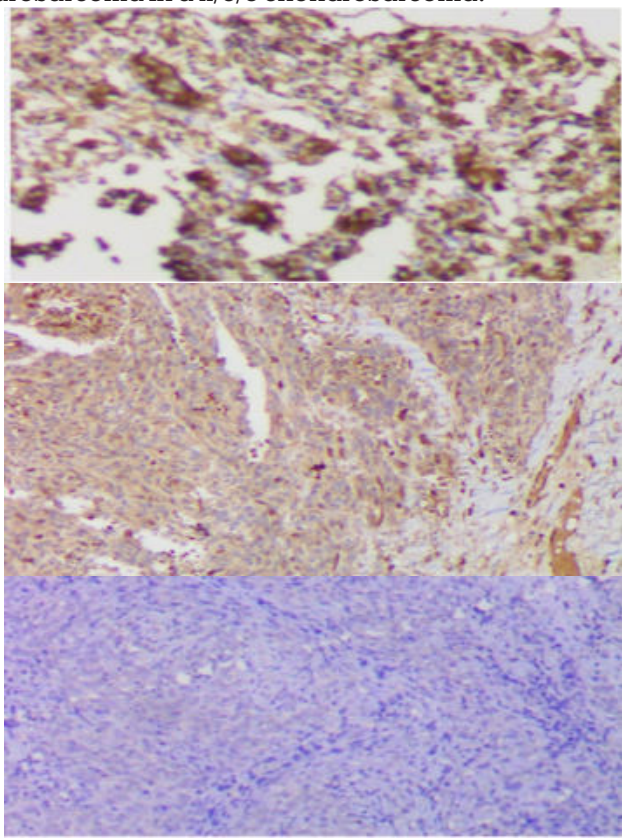

Fig $3 a, 3 b$ and $3 c$ depicting Immuno Histochemistry results.

\section{DISCUSSION}

Lung metastases are of particular poor prognosis among patients with primary osseous neoplasms. It is assumed that approximately $10-40 \%$ of the patients have detectable lung metastases at diagnosis of malignant primary osseous neoplasms.

Primary osseous neoplasms are rare malignancies in the bone. Some of the more common malignant tumors include osteosarcoma, Ewing sarcoma, chondrosarcoma, and chordoma. Lung metastasis was the poor survival factor in these patients . Death from malignant bone tumors is usually the result of progressive lung metastasis with respiratory failure secondary to widespread disease. The incidence of lung metastasis was $18.8 \%$ (Ewing sarcoma), $15.9 \%$ (osteosarcoma), 5.3\% (chondrosarcoma), and $1.1 \%$ (chordoma)

Chondrosarcoma is the second most frequent primary malignant bone sarcoma . However, it is considered that metastasis is less common in patients with chondrosarcoma, while patients with chondrosarcoma and higher grade have more chance of lung metastases. The rate of metastasis is related to histological tumor grade. It is also identified higher tumor grade as an independent risk factor for lung metastasis at diagnosis. Previous studies reported that $40-60 \%$ of patients of the high-grade sarcomas will develop lung metastases, of which $70-80 \%$ will have disease limited to lungs, likely through hematogenous spread. ${ }^{3}$

The incidence of metastasis to lung in a Low grade chondrosacoma is rare and is depicted in this case scenario.

Risk factors for lung metastasis at presentation with malignant primary osseous neoplasms: a population-based study $^{4}$

Table 2:

\begin{tabular}{|l|l|}
\hline Characteristic & $\begin{array}{l}\text { Number (\%) of patients with lung } \\
\text { metastases }\end{array}$ \\
\hline Histology type & \\
\hline Ewing sarcoma & $111(18.8)$ \\
\hline Osteosarcoma & $232(15.9)$ \\
\hline Chondrosarcoma & $69(5.3)$ \\
\hline Chordoma & $5(1.1)$ \\
\hline Tumor size & \\
\hline & $29(2.8)$ \\
\hline$\geq 5 \mathrm{~cm}$ & $358(13.4)$ \\
\hline Grade & \\
\hline Low & $27(2.4)$ \\
\hline High & $263(16.4)$ \\
\hline
\end{tabular}

\section{CONCLUSIONS}

The present case study identified lung metastases in patient with primary osseous neoplasm. Even after the complete excision of the primary tumor, screening of the whole body PET SCAN is necessary as after a latency period of 4-5yrs, the incidence of recurrance or metastasis is possible. Hence a Periodical screening is required for detection at early stage and treatment. Low dose CT scan at $3^{\text {rd }}$ month annually required for screening for lung cancer. If any increase in nodular size, shape and attenuation, early intervention as biopsy is mandatory.It would be helpful for clinicians to evaluate patients' risk of lung metastasis and counsel patients regarding the possibility of lung metastasis at diagnosis.

\section{REFERENCES}

1. Malaysian Orthopaedic Journal 2015 Vol 9 No 2

2. Alessandro Franchi. Epidemiology and classification of bone tumors. Clinical Cases in Mineral and Bone Metabolism 2012; 9(2): 92-5. 2.

3. World Health Organization. Cartilage Tumours. In: Fletcher CDM, Uni KK Mertens F, eds. World Health Organization Classification of Tumours. Pathology and Genetics. Tumours of Soft Tissue and Bone. Lyon, France: IARC Press, 2002: 234-57

4. Journal of Orthopaedic Surgery and ResearchISSN: 1749-799X 